\title{
EDITORIAL \\ CEJOR special issue: dynamic optimization in management and economics
}

\section{Reinhard Neck ${ }^{1}$}

Published online: 12 March 2020

c) Springer-Verlag GmbH Germany, part of Springer Nature 2020

November 15, 2018, the Austrian Research Association (Österreichische Forschungsgemeinschaft, ÖFG) awarded its bi-annual Science Prize to Gustav Feichtinger, professor emeritus at the University of Technology, Vienna. Gustav Feichtinger was a pioneer in developing and applying methods of dynamic optimization (optimal control theory and dynamic programming) for problems in the social and economic sciences, in particular management and economics; in addition, he worked on topics in demography, operations research, stochastic analysis and others. The number and quality of his publications is outstanding and still increasing at a rate which could make a younger scholar proud of himself. One of the most remarkable achievements, however, is the large number of former students he made fit for becoming successful scientists. Among them are more professors of economics and management than among students of most other scientists in these fields.

Therefore the ÖFG decided to honor Gustav Feichtinger not only by the prize but also by a symposium with contributions from several of his former students and some close friends. The topic of the symposium was dynamic optimization in management and economics, on which he started to work more than 40 years ago as one of the first Austrian social scientists and to which he contributed so many insights and followers. In contrast to many other areas of applied mathematics, methods of dynamic optimization are still among the toolkits of mathematical economists today. Just recently, they were increasingly used to solve problems in operations research and economics; see, e.g. Blueschke et al. (2019), Ghoreishi (2019), Grames et al. (2019), Inderfurth et al. (2018), Leitold et al. (2019), Ozolins (2019), Ulmer (2020).

The papers in this special issue of the Central European Journal of Operations Research cover a wide range of topics close to the interests of Gustav; most of the papers were presented by his former students and long-time friends at the symposium organized by the ÖFG on the occasion of the award. All papers were subjected to

Reinhard Neck

Reinhard.Neck@aau.at

1 Department of Economics, Alpen-Adria-Universität Klagenfurt, Universitätsstraße 65-67,

9020 Klagenfurt, Austria 
the usual refereeing procedure of the journal and revised according to the referees' suggestions.

The keynote presentation by the awardee at the symposium was further developed into the paper by Gustav Feichtinger et al. (2020) on ageing in academia, which combines methods of operations research and of demography. It deals with the optimal scientific production over the life cycle of researchers and with the dynamics of the age structure of scientific institutions, exemplified with the Austrian Academy of Sciences. Miguel Sánchez-Romeo and Alexia Prskawetz (2020), inspired by Gustav Feichtinger's productivity development, model the optimal time allocation of a university professor over the life cycle, in particular during the retirement phase of his life. The parameters of their model are calibrated to Gustav's data, and they provide him with decision support for his activities during the next decades. In another study at the intersection of evolutionary modelling and dynamic optimization, Otwin Becker and Ulrike Leopold-Wildburger (2020) consider several economic applications of Lotka-Volterra predator-prey systems and characterize trade-offs when optimizing such systems over time.

Most economic applications of dynamic optimization methods so far centered upon microeconomic problems, in particular problems in the theory of the firm. Bertrand Crettez et al. (2020) characterize dynamic pricing strategies of a firm when demand depends on a reference (mental, expected) price. Motivated by the recent scandal concerning car emissions, Markus Eigruber and Franz Wirl (2020) investigate how firms cheat about attributes of their products in markets of monopoly, cartel and duopoly, applying a dynamic game with different open-loop and Markov perfect equilibria. A dynamic duopoly is also considered by Herbert Dawid et al. (2020) to model the competition between two firms, where one of them invests more in research and development of a new product than the other, innovates first and gets a patent. Optimal intertemporal decisions of firms producing durable goods are the subject of the paper by Richard Hartl et al. (2020). They show how these firms have to combine continuoustime operational level planning with discrete decision making when deciding about pricing, capacity investment and introducing new products.

In some cases also macroeconomic and financial problems can be treated successfully by intertemporal decision methods. Gerhard Sorger (2020) extends an analysis by Miao and Wang (2018) of stock price bubbles caused by endogenous collateral constraints to the case of a risk averse household. Dmitri Blueschke et al. (2020) analyze a dynamic game of fiscal and monetary policy making in a monetary union and determine numerically Markov perfect equilibrium and Pareto optimal solutions for the problem of dealing with increasing government debt after a demand shock, showing that debt reliefs may involve disadvantages to both the debtor and the creditor country and an unstable and unsustainable debt development. Finally, Mikuláš Luptáčik and Eduard Nežinský (2020) propose a new indicator for the measurement of inequality of the personal income distribution based on a DEA (data envelopment analysis) approach and apply it to an intertemporal analysis of income distribution and growth in 29 European countries.

We hope that the present collection of studies using methods of dynamic optimization and related techniques to problems of demography, microeconomics, macroeconomics and operations research contributes to obtain further insights into 
the broad varieties of topics of interest to Gustav Feichtinger and his many friends and show the potential of these methods for analyzing intertemporal decision problems in the social sciences.

\section{References}

Becker O, Leopold-Wildburger U (2020) Optimal dynamic control of predator-prey models. CEJOR. https:// doi.org/10.1007/s10100-019-00656-7

Blueschke D, Weyerstrass K, Neck R, Majcen B, Srakar A, Verbič M (2019) Budget consolidation in a small open economy: a case study for Slovenia. Post-Communist Econ 31(3):325-348. https://doi. org/10.1080/14631377.2018.1537735

Blueschke D, Neck R, Wittmann A (2020) How relieving is public debt relief? Monetary and fiscal policies in a monetary union during a debt crisis. CEJOR. https://doi.org/10.1007/s10100-020-00677-7

Crettez B, Hayek N, Zaccour G (2020) Existence and characterization of optimal dynamic pricing strategies with reference-price effects. CEJOR. https://doi.org/10.1007/s10100-019-00645-w

Dawid H, Kopel M, Kort PM (2020) Product innovation with partial capacity rollover. CEJOR. https://doi. org/10.1007/s10100-019-00648-7

Eigruber M, Wirl F (2020) Cheating as a dynamic marketing strategy in monopoly, cartel and duopoly. CEJOR. https://doi.org/10.1007/s10100-019-00652-x

Feichtinger G, Grass D, Winkler-Dworak M (2020) The mathematics of ageing: linking demography and operations research to study the greying of academia. CEJOR. https://doi.org/10.1007/s10100-019-0 0661-w

Ghoreishi M (2019) Testing the robustness of deterministic models of optimal dynamic pricing and lotsizing for deteriorating items under stochastic conditions. CEJOR 27:1131-1152. https://doi.org/10.1 007/s10100-018-0538-7

Grames J, Grass D, Kort PM, Prskawetz AA (2019) Optimal investment and location decisions of a firm in a flood risk area using impulse control theory. CEJOR 27:1051-1077. https://doi.org/10.1007/s1010 0-018-0532-0

Hartl RF, Kort PM, Seidl A (2020) Decisions on pricing, capacity investment, and introduction timing of new product generations in a durable-good monopoly. CEJOR. https://doi.org/10.1007/s10100-019-0 0659-4

Inderfurth K, Kelle P, Kleber R (2018) Inventory control in dual sourcing commodity procurement with price correlation. CEJOR 26:93-119. https://doi.org/10.1007/s10100-017-0475-X

Leitold D, Vathy-Fogarassy A, Abonyi J (2019) Empirical working time distribution-based line balancing with integrated simulated annealing and dynamic programming. CEJOR 27:455-473. https://doi.org/ 10.1007/s10100-018-0570-7

Luptáčik M, Nežinský E (2020) Measuring income inequalities beyond the Gini coefficient. CEJOR. https:// doi.org/10.1007/s10100-019-00662-9

Miao J, Wang P (2018) Asset bubbles and credit constraints. Am Econ Rev 108:2590-2628

Ozolins A (2019) Improved bounded dynamic programming algorithm for solving the blocking flow shop problem. CEJOR 27:15-38. https://doi.org/10.1007/s10100-017-0488-5

Sánchez-Romeo M, Prskawetz A (2020) Optimal time allocation in active retirement. CEJOR. https://doi. org/10.1007/s10100-019-00663-8

Sorger G (2020) On the dynamics of stock price bubbles: comments on a model by Miao and Wang. CEJOR. https://doi.org/10.1007/s10100-019-00650-z

Ulmer MW (2020) Horizontal combinations of online and offline approximate dynamic programming for stochastic dynamic vehicle routing. CEJOR 28:279-308. https://doi.org/10.1007/s10100-018-0588-X

Publisher's Note Springer Nature remains neutral with regard to jurisdictional claims in published maps and institutional affiliations. 